\title{
An evaluation of sotalol, a $\beta$-blocking agent, in patients with angina pectoris
}

\author{
P. G. GoOdING \\ M.B., B.S. \\ E. BERMAN \\ M.B., CH.B.
Medical Department, Bristol-Myers Company, International Division, New York

\begin{abstract}
Summary
In a multi-centre study, sotalol was compared with placebo in 146 patients with angina pectoris using a double-blind crossover design. Sotalol had a significant effect in reducing the number of anginal attacks and the number of nitroglycerin tablets used. The medication was safe and produced minimal side effects.
\end{abstract}

\section{Introduction}

$\beta$-Receptor-blocking agents such as propranolol have been shown to decrease the frequency of anginal attacks in patients suffering from angina pectoris (Dollery, Paterson and Conolly, 1969; Neilson and Seldon, 1969; Aronow, 1972). Sotalol, an alkylsulphonamido-phenethanolamine, has several advantages over other $\beta$-blockers. It possesses pure $\beta$-blocking activity, but lacks the intrinsic sympathomimetic activity and quinidine-like effect of other $\beta$-blockers (Lish, Weikel and Dungan, 1965; Raper and Wale, 1968). Additionally, unlike propranolol, sotalol possesses little myocardial depressant activity (Brooks et al., 1970; Stanton, Kirchgessner and Parmenter, 1965; Levy and Richards, 1965).

It was therefore decided to conduct a multi-centre study to compare sotalol given orally with a placebo in patients with angina pectoris using a double-blind crossover technique. A preliminary analysis of the findings in 146 patients is the subject of this report; further details will be presented in a subsequent paper.

\section{Methods}

Patients suffering from angina pectoris, as confirmed by a classical history and by electrocardiographic changes, were included in the study. Excluded from the study were patients with hyperthyroidism, bronchial asthma, myocardial infarction within the preceding 3 months, uncompensated heart failure, previous cardiac surgery, second and third degree heart block, a resting pulse rate below $60 / \mathrm{min}$, or severe hepatic or renal impairment.

Correspondence: Medical Department, Bristol-Myers Company, International Division, 345 Park Avenue, New York, New York 10022.
All patients were treated on an outpatient basis Throughout the study the patients were allowed to use sublingual nitroglycerin to relieve anginal attacks, but not for prophylactic use. No long-acting nitrates or other medications which might affect the response to therapy were permitted.

Each patient was studied for a total of 20 weeks. For the first 6 weeks, the patients received placebo tablets, 1 tablet four times daily, in order to establish a baseline as to the frequency of anginal attacks. The patients were also given daily diaries in which to record the number of attacks, and the number of nitroglycerin tablets taken for relief. If at the end of the first 3 weeks the diary showed an average incis dence of fewer than four attacks per week, the patient was excluded from the study.

A 2-week titration period followed during which all patients were treated with increasing doses of sotalol, starting with $160 \mathrm{mg} /$ day and increasing up to a maximum of $480 \mathrm{mg} /$ day. The dose was adjusted according to each patient's individual response.

Following the titration period, the patients were assigned at random on a double-blind basis to either sotalol or placebo medication for a 6-week treatment period. During this time the patient received the same number of tablets per day as he was taking at the end of the titration period (i.e. his optimum dose). At the end of 6 weeks, the patients were switched to the other medication for a second 6-week treatment period.

The patients were examined every third week, except during the titration period when they were examined weekly. At each examination the pulse rate and blood pressure in the erect and supine positions were recorded, as well as electrocardiograms. Additionally, haematological and biochemical parameters were monitored.

\section{Results}

A total of 146 patients (103 men, forty-three women) were included in the study. The patients ranged in age from 34 to 79 years, with a mean age of 55 years. During both titration and treatment periods, the dose of sotalol ranged from 120 to 
$480 \mathrm{mg} /$ day. The optimum daily dose for 135 of the 146 patients $(92.5 \%)$ was between 240 and $480 \mathrm{mg}$ (3-6 $80 \mathrm{mg}$ tablets). The optimum daily dose for ten of the remaining patients was $160 \mathrm{mg}$; for the eleventh, $120 \mathrm{mg}$.

The order in which the treatments were given during the two 6-week treatment periods (i.e. sotalol followed by placebo or placebo followed by sotalol) had no effect on the patients' response; the results were similar in both groups. Thus, the data were combined.

Table 1 shows the mean values obtained in all patients during the baseline, sotalol, and placebo periods for the following parameters: number of anginal attacks per week, number of nitroglycerin tablets consumed per week, pulse rate per minute, and systolic and diastolic blood pressures.

TABLE 1. Mean values obtained during various test periods in all patients irrespective of dose

\begin{tabular}{|c|c|c|c|}
\hline Parameter & Baseline & Sotalol & Placebo \\
\hline $\begin{array}{l}\text { Number of anginal attacks } \\
\text { per week }\end{array}$ & $12 \cdot 5$ & $5 \cdot 1$ & $8 \cdot 0$ \\
\hline $\begin{array}{l}\text { Number of nitroglycerin } \\
\text { tablets consumed per week }\end{array}$ & $12 \cdot 3$ & $4 \cdot 5$ & $6 \cdot 9$ \\
\hline $\begin{array}{l}\text { Pulse rate/minute } \\
\text { Erect } \\
\text { Supine }\end{array}$ & $\begin{array}{l}82 \cdot 7 \\
81 \cdot 2\end{array}$ & $\begin{array}{l}69 \cdot 0 \\
67 \cdot 2\end{array}$ & $\begin{array}{l}76 \cdot 5 \\
74 \cdot 3\end{array}$ \\
\hline $\begin{array}{l}\text { Systolic blood pressure } \\
\text { (mmHg) } \\
\text { Erect } \\
\text { Supine }\end{array}$ & $\begin{array}{l}148 \cdot 3 \\
149 \cdot 0\end{array}$ & $\begin{array}{l}139 \cdot 6 \\
141 \cdot 7\end{array}$ & $\begin{array}{l}142 \cdot 8 \\
144 \cdot 4\end{array}$ \\
\hline $\begin{array}{l}\text { Diastolic blood pressure } \\
\text { (mmHg) } \\
\text { Erect } \\
\text { Supine }\end{array}$ & $\begin{array}{l}86 \cdot 1 \\
86 \cdot 0\end{array}$ & $\begin{array}{l}80 \cdot 4 \\
80 \cdot 3\end{array}$ & $\begin{array}{l}83 \cdot 3 \\
83 \cdot 2\end{array}$ \\
\hline
\end{tabular}

A striking reduction in the number of attacks of angina pectoris during sotalol treatment when compared to the baseline period was observed in 137 $(93.8 \%)$ of the 146 patients. The mean number of attacks was decreased by $50 \%$ or more in 104 of the patients $(71.2 \%)$ when compared to the baseline period and in seventy-six of the patients $(52 \cdot 1 \%)$ when compared to the placebo period.

Similarly, there was a marked decrease in the number of nitroglycerin tablets taken during treatment with sotalol. The decrease in nitroglycerin consumption paralleled the decrease in the number of anginal attacks observed during this period. Of the 138 patients using nitroglycerin during the baseline period, $89 \%$ consumed fewer tablets while taking sotalol, and $69.6 \%$ used less nitroglycerin while taking sotalol than while taking placebo. The number of tablets taken was reduced by $50 \%$ or more in $67.8 \%$ of the patients during the sotalol treatment period when compared to the baseline period, and in $40.4 \%$ of the patients when compared to the placebo period.

Sotalol caused a significant slowing of the pulse rate in both the supine and erect positions. The mean pulse rate was reduced by $14-20 \%$, but the reduction was not dose-related.

The supine and erect systolic and diastolic pressures during both the titration and sotalol treatment periods were lower than during the baseline period. However, no significant differences between the systolic and diastolic pressures during the sotalol and placebo periods were demonstrated. Overall, sotalol was well tolerated. Two patients reported dyspnoea on effort at different times during the study. In a third patient there was evidence of incipient cardiac failure before treatment, with aggravation during the treatment period with sotalol. However, sotalol was continued and the cardiac failure was reversed by the use of a thiazide diuretic. Additionally, the following symptoms were reported by seven patients, one symptom per patient: weakness, dizziness, headache, fever, ache in the legs, palpitation, and 'feeling bad'. No significant alterations in any of the laboratory tests performed during the study were noted.

\section{Discussion}

The effectiveness of sotalol in preventing attacks of angina pectoris is shown (Table 1) by comparing the mean number of attacks during the baseline and placebo periods with the mean during the sotalol treatment period. These differences are significant $(P=0.01)$.

The mean number of anginal attacks remained remarkably constant during the 6-week baseline period. The extent of the clinical improvement is indicated by the fact that $71.2 \%$ of the patients reported a reduction of $50 \%$ or more in the number of attacks during the sotalol treatment period when compared to the baseline period. The reduction in the number of attacks is confirmed by the decrease in the consumption of nitroglycerin. These findings are in sharp contrast to those obtained by others (Alderman et al., 1973) with the $\beta$-blocking agent, practolol. In a limited clinical trial in eight patients, treatment with practolol failed to produce any statistically significant change in the frequency of anginal attacks (Alderman et al., 1973).

The optimum dose of sotalol was $240-480 \mathrm{mg}$ in 135 of the 146 patients $(92.5 \%)$. In most cases this dose was reached within 2 or 3 weeks. Occasionally, the dose had to be increased or decreased slightly several weeks later.

The sotalol regimen was well tolerated and the incidence of side effects was low. It is felt that sotalol, unlike propranolol (Aronow, 1972), may 
generally be used safely in patients with controlled cardiac failure, as studies (Brooks et al., 1970) have shown that sotalol-induced $\beta$-blockade has no adverse haemodynamic effects in cardiac patients, even when advanced chronic cardiac failure is present. That the cardiac failure in one patient in this series was reversed by the use of a thiazide diuretic during continued treatment with sotalol tends to confirm these findings.

Further details of this investigation will be presented in a subsequent paper. However, the preliminary analysis of the data suggests that sotalol is of value in the treatment of patients with angina pectoris.

\section{References}

Alderman, E.L., Davis, R.O., Friedman, J.P., Graham, A.F., Matlof, H.J. \& Harrison, D.C. (1973) Practolol in patients with angina pectoris. Clinical Pharmacology and Therapeutics, 14, 175.
ARoNow, W.S. (1972) The medical treatment of angina pectoris VI. Propranolol as an antianginal drug. American Heart Journal, 84, 706.

Brooks, H., Banas, J. JR, Meister, S., Szucs, M. JR, Dalen, J. \& Dexter, L. (1970) Sotalol-induced beta blockade in cardiac patients. Circulation, 42, 99.

Dollery, C.T., Paterson, J.W. \& Conolly, M.E. (1969) Clinical pharmacology of beta-receptor-blocking drugs. Clinical Pharmacology and Therapeutics, 10, 765.

LEVY, J.V. \& RICHARDS, V. (1965) Inotropic and metabolic effects of three beta-adrenergic receptor blocking drugs on isolated rabbit left atria. The Journal of Pharmacology and Experimental Therapeutics, 150, 361.

Lish, P.M., Weikel, J.H. \& Dungan, K.W. (1965) Pharmacological and toxicological properties of two new $\beta$ adrenergic receptor antagonists. The Journal of Pharmacology and Experimental Therapeutics, 149, 161.

Neilson, G.H. \& Seldon, W.A. (1969) Propranolol in angina pectoris. The Medical Journal of Australia, 5, 856.

RAPER, C. \& WALE, J. (1968) Propranolol, MJ 1999 and CIBA $39089 \mathrm{Ba}$ in ouabain and adrenaline induced cardiac arrhythmias. European Journal of Pharmacology, 4, 1.

Stanton, H.C., Kirchgessner, T. \& Parmenter, K. (1965) Cardiovascular pharmacology of two new $\beta$-adrenergic receptor antagonists. The Journal of Pharmacology and Experimental Therapeutics, 149, 174. 